\title{
Synthesis of metallic nanoparticles from Beta vulgaris using a single-pot green chemistry approach and their environmental engineering application
}

\author{
Carol Zethu Ngwenya ${ }^{1} \cdot$ Karabo Seteno Obed Ntwampe $^{1}$ (D) Nothemba Silwana $^{1}$
}

Received: 1 July 2016/Accepted: 26 October 2016/Published online: 3 November 2016

(C) Springer International Publishing Switzerland 2016

\begin{abstract}
In this study, a method for the green synthesis of nanoparticles using Beta vulgaris (B. vulgaris) extracts was developed. B. vulgaris was solely used in a synthetic, chemical-free, redox reaction, as a source of the precursor metal, reducing and capping agent. Metals accumulated in $B$. vulgaris were reduced to nanosize by betanin, an anthocyanin present in the B. vulgaris which has reducing and stabilising capabilities. Nanoparticles were synthesised in a solution containing $1 \%(\mathrm{v} / \mathrm{v})$ B. vulgaris juice extract, at $80{ }^{\circ} \mathrm{C}$ and a $\mathrm{pH}$ of 8 . The nanoparticles were characterised using TEM, SEM-EDS, UV-Vis, FTIR, and PXRD. It was determined that a hydroxyl group from the betanin releases an active $\mathrm{H}^{+}$proton, which subsequently reduces metal ions. Results showed that spherical-shaped Ca-based crystal nanoparticles of approximately $5 \mathrm{~nm}$ were successfully synthesised using the developed method. Supplementing the Ca-based nanoparticles in biosurfactant producing cultures of Bacillus licheniformis STK 01 improved the emulsification index of kerosene from 20 to $50 \%$ - signifying the usability of the nanoparticles in environmental engineering applications in which hydrophobic compounds are targeted for bioremediation.
\end{abstract}

Keywords Beta vulgaris - Betanin · Environmental engineering $\cdot$ Nanobiotechnology $\cdot$ Nanoparticles

Karabo Seteno Obed Ntwampe

NtwampeS@cput.ac.za

1 Bioresource Engineering Research Group (BioERG), Department of Biotechnology, Cape Peninsula University of Technology, P.O. Box 652, Cape Town 8000, South Africa

\section{Introduction}

Nanoparticles, due to their ideal particle size and unique properties, have been of great research interest for applications in the field of biotechnology. The focus has been on the active integration of microbial biotechnology and nanotechnology [23]. Current trends also focus on the application of nanoparticles to improve biochemical processes. For example, iron $(\mathrm{Fe})$ nanoparticles increased glycolipid biosurfactant production by $80 \%$ using Nacardiopsis sp. MSA13A [13] with the produced biosurfactant being used as green stabilisers for the biological synthesis of nanoparticles [14]. This indicates the need for the synthesis of suitable nanoparticles for biochemical processes and environmental engineering applications.

Nanoparticles are highly reactive, and their characteristics depend on their particle size, shape, and composition. Nanoparticles are synthesised by different physical and chemical methods. They can either be synthesised using a top-down approach which involves the breaking down of a large particle into nanosize, or a bottom-up approach, whereby atoms are assembled to molecular structures that fall within the nanorange [23]. The most commonly used method is the chemical reduction method that involves reducing metal salts to metal atoms by using a reducing agent. The currently employed chemical and physical processes for nanoparticle synthesis are labour-intensive, use high radiation, temperature, and pressure, as well as analytical grade chemicals as reducing and stabilising agents. The residue and/or waste from such processes can become detrimental to environmental health and living organisms when disposed-off into the environment. Thus, the synthesis of nanoparticles using the green chemistry approach is therefore recommended. Research has focused on the development of clean, non-toxic and 
environmentally benign production processes for nanoparticle synthesis. There have been many reported attempts at synthesising nanoparticles in supposedly environmentally friendly, non-toxic processes that promote the green chemistry approach $[9,17]$. For the green chemistry approach, biological/plant extracts are used to replace hazardous chemicals, mostly as reducing and stabilising agents.

In a study by Gan et al. [9], palm oil mill effluent was used as a reducing agent for the synthesis of gold nanoparticles from a chloroauric acid solution $\left(\mathrm{HAuCl}_{4}\right)$ as a metal precursor. However, this approach still produces toxic chemical waste from the source of the metal precursor. Similarly, Le et al. [17] produced silica nanoparticles from Vietnamese rice husks as a source of the metal precursor but used analytical grade chemicals as reducing and stabilising agents. Additionally, numerous studies have reported on the green synthesis of silver nanoparticles particularly as a noble metal with vast applications $[4,7,8,10,26]$. In these studies, various plant extracts have shown potential to facilitate the bioreduction of the silver-based metal precursor to silver nanoparticles [1]. This approach has been widely used for the green synthesis of silver nanoparticles. However, the major setback of these methods is that most reported using analytical grade $\mathrm{AgNO}_{3}$ as a precursor. Upon bioreduction of $\mathrm{Ag}^{2+}$ to $\mathrm{Ag}-$ NPs, the $\mathrm{NO}_{3}{ }^{2-}$ is most likely to end-up in wastewater. This may result in pollution of freshwater sources by causing eutrophication and acidification [25]. Alternatively, agrowaste material such as Beta vulgaris, which is known to contain various metals [2] including reducing agents [27], can be used for the synthesis of nanoparticles. This approach to green synthesis of nanoparticles can add to the current methods being developed for the synthesis of nanoparticles intended for environmental engineering applications.

As previously mentioned that $B$. vulgaris has been shown to be a rich source of metals and valuable compounds such as betanin with high metal ion reducing capabilities [22], the present study was undertaken to develop a single-pot method for the green synthesis of nanoparticles from B. vulgaris.

\section{Experimental methods and materials}

\section{Preparation of Beta vulgaris solutions for nanoparticle synthesis}

B. vulgaris extract solution was prepared from $B$. vulgaris agrowaste obtained from a fruit- and vegetable-processing facility located in Cape Town, Western Cape, South Africa. The facility is located within close proximity of the Cape
Peninsula University of Technology, District Six campus. The waste was milled and oven-dried at $70{ }^{\circ} \mathrm{C}$ for $72 \mathrm{~h}$, and thereafter, it was pulverised to a size less than $0.30 \mathrm{~mm}$. A mass of $10 \mathrm{~g}$ of the pulverised B. vulgaris was added to $1 \mathrm{~L}$ of sterile distilled water $\left(\mathrm{sdH}_{2} \mathrm{O}\right)$. Additionally, a juice extract was obtained by juicing freshly peeled B. vulgaris tubers in a blender (Russell Hobbs ${ }^{\mathrm{TM}}$, England), and the removal of $B$. vulgaris debri was achieved by filtering all the solutions including juice extracts through a 125 -mm Whatman ${ }^{\circledR}$ filter paper.

\section{Preparation of an Aloe vera solution to enhance nanoparticle synthesis}

Aloe vera (A. vera) was obtained within the premises of the Cape Peninsula University of Technology, District Six campus. A. vera contains bioactive phytochemicals that can facilitate nanoparticle formation. The $A$. vera leaf was cut into small fractions, and $20 \mathrm{~g}$ of the sliced A. vera was added to $200 \mathrm{~mL}$ of $\mathrm{sdH}_{2} \mathrm{O}$. An A. vera extract solution was prepared by boiling at $100{ }^{\circ} \mathrm{C}$ for $60 \mathrm{~min}$. The solution was filtered through a $125-\mathrm{mm}$ Whatman ${ }^{\circledR}$ filter paper to remove debri prior to usage.

\section{Preparation of $\mathrm{CaCO}_{3}$ solution from egg shells for $\mathrm{pH}$ adjustment}

Eggshells were obtained from a campus restaurant of the Cape Peninsula University of Technology, District Six campus. The eggshells were washed in running tap water and oven-dried at $70{ }^{\circ} \mathrm{C}$ for $24 \mathrm{~h}$ and milled to produce a fine powder. A mass of $50 \mathrm{~g}$ of powdered eggshells was added to $100 \mathrm{~mL}$ of $\mathrm{sdH}_{2} \mathrm{O}$ and autoclaved at $121{ }^{\circ} \mathrm{C}$ for 15 min and filtered through a $125-\mathrm{mm}$ Whatman ${ }^{\circledR}$ paper. The eggshell solution was used to adjust the $\mathrm{pH}$ of some solutions used in this study.

\section{Process conditions assessed for the synthesis of nanoparticles}

Experimental runs $(n=13$, in triplicate-see Table 1) were used to optimise $\mathrm{pH}$, juice extract/solution concentration, and temperature for the synthesis of nanoparticles. The $\mathrm{pH}$ was tested at acidic (low/high acidity) and alkaline (low/high alkalinity) conditions. The $\mathrm{pH}$ adjustment was accomplished by either using $1 \mathrm{M} \mathrm{NaOH}$ and/or $\mathrm{CaCO}_{3}$ extracted from eggshells (for the alkaline study), while $1 \mathrm{M}$ $\mathrm{HCl}$ was utilised for the studies conducted under acidic conditions. The temperature used was either at room temperature (RT) or at $80{ }^{\circ} \mathrm{C}$ [22]. The presence and synthesis of nanoparticles was initially determined by a colorimetric technique [12], as the interaction of plant extracts with metal ions in solution alters the properties of the extract, 
Table 1 Process parameters for determining suitable conditions for the synthesis of nanoparticles

\begin{tabular}{llrlll}
\hline Sample ID & Temperature & $\mathrm{pH}$ & B. vulgaris solution/juice & BV:AV ratio & pH adjusting solution \\
\hline 1 & $\mathrm{RT}$ & 2 & $10 \mathrm{~mL}$ extract solution & $1: 0$ & $1 \mathrm{M} \mathrm{HCl}$ \\
2 & $\mathrm{RT}$ & 6 & $10 \mathrm{~mL}$ extract solution & $1: 0$ & $1 \mathrm{M} \mathrm{HCl}$ \\
3 & $\mathrm{RT}$ & 8 & $10 \mathrm{~mL}$ extract solution & $1: 0$ & $1 \mathrm{M} \mathrm{NaOH}$ \\
4 & $\mathrm{RT}$ & 10 & $10 \mathrm{~mL}$ extract solution & $1: 0$ & $1 \mathrm{M} \mathrm{NaOH}$ \\
5 & $80{ }^{\circ} \mathrm{C}$ & 2 & $10 \mathrm{~mL}$ extract solution & $1: 0$ & $1 \mathrm{M} \mathrm{HCl}$ \\
6 & $80^{\circ} \mathrm{C}$ & 6 & $10 \mathrm{~mL}$ extract solution & $1: 0$ & $1 \mathrm{M} \mathrm{HCl}$ \\
7 & $80^{\circ} \mathrm{C}$ & 8 & $10 \mathrm{~mL}$ extract solution & $1: 0$ & $1 \mathrm{M} \mathrm{NaOH}$ \\
8 & $80^{\circ} \mathrm{C}$ & 10 & $10 \mathrm{~mL}$ extract solution & $1: 0$ & $1 \mathrm{M} \mathrm{NaOH}$ \\
9 & $80{ }^{\circ} \mathrm{C}$ & 8 & $10 \mathrm{~mL}$ extract solution & $1: 1$ & $\mathrm{CaCO} / \mathrm{EgS}$ \\
10 & $80^{\circ} \mathrm{C}$ & 8 & $100 \%(\mathrm{v} / \mathrm{v})$ juice extract & $1: 0$ & $1 \mathrm{M} \mathrm{NaOH}$ \\
11 & $80^{\circ} \mathrm{C}$ & 8 & $10 \%(\mathrm{v} / \mathrm{v})$ juice extract & $1: 0$ & $1 \mathrm{M} \mathrm{NaOH}$ \\
12 & $80^{\circ} \mathrm{C}$ & 8 & $1 \%(\mathrm{v} / \mathrm{v})$ juice extract & $1: 0$ & $1 \mathrm{M} \mathrm{NaOH}$ \\
13 & $80^{\circ} \mathrm{C}$ & 8 & $0.1 \%(\mathrm{v} / \mathrm{v})$ juice extract & $1: 0$ & $1 \mathrm{M} \mathrm{NaOH}$
\end{tabular}

$R T$ room temperature, $B V B$. vulgaris, $A V A$. vera, $E g S$ eggshell

All experiments were performed in triplicate resulting in a colour change. Subsequently, favourable process conditions were identified.

\section{The effect of $A$. vera on nanoparticle synthesis}

The effect of $A$. vera in the synthesis of nanoparticles was evaluated (experimental run 9, Table 1), with the A. vera solution being added to the $B$. vulgaris extract solution at a ratio of 1:1. The $\mathrm{CaCO}_{3}$ solution from eggshell extract solution was used to adjust the $\mathrm{pH}$ of the media.

\section{Nanoparticle synthesis from $B$. vulgaris solutions and juice extract}

A comparative study between the $B$. vulgaris agrowaste extract solutions and the juice extract solution was evaluated. Different concentrations of juice extract were evaluated (see Table 1, experimental runs 10-13). The reaction was carried out at optimised $\mathrm{pH}$ and temperature, and the presence of nanoparticles was assessed based on the colour change in the solutions and reaction time.

\section{Purification and characterisation of nanoparticles}

Nanoparticle purification was done according to a method developed by Kowalczyk et al. [15], which is based on centrifugation. Briefly, samples were centrifuged at $1400 \mathrm{rpm}$ for $10 \mathrm{~min}$ at a temperature of $4{ }^{\circ} \mathrm{C}$, followed by pellet re-suspension in deionised water to remove $B$. vulgaris debri and extracellular polymeric substances (EPS). The supernatant was discarded, and the pellet was dried at $60{ }^{\circ} \mathrm{C}$ for $24 \mathrm{~h}$. The dried pellet was then used for characterisation using microscopy and spectrophotometric techniques. The IR spectra of the nanoparticles were measured using a PerkinElmer FTIR spectrometer with a scan range of $7800-4000 \mathrm{~cm}^{-1}$ while a UV-Vis spectrophotometer was used to determine the absorption spectra in the range of $200-800 \mathrm{~nm}$.

Furthermore, powder X-ray diffraction was used to determine the diffraction pattern and crystalline properties of the particles using a D2 Phaser BRUKER diffractometer with $\mathrm{Cu}-\mathrm{K} \alpha(1.54184 \AA)$. The size and shape of the nanoparticles was determined using a FEI/Tecnai T20 TEM operated at $200 \mathrm{kV}$, with further confirmation being done using a Zeiss/Leo 1450 SEM-EDS, which also aided with the elemental analysis. Additionally, ImageJ software was utilised to analyse 2D TEM images, by initially setting the scale as enlisted on the images, to further quantify the particle size distribution of the nanoparticles, using the analysis tool within the software [16].

\section{Environmental engineering application: biosurfactant activity by emulsifying kerosene}

A volume of $5 \mathrm{~mL}$ of kerosene was added to $5 \mathrm{~mL}$ of the cell-free supernatant, recovered at $11000 \mathrm{~g}$ for $10 \mathrm{~min}$, containing the biosurfactant produced by Bacillus licheniformis STK 01 using $B$. vulgaris media supplemented with nanoparticles in a graduated $15-\mathrm{mL}$ centrifuge tube. The mixture was mixed using a vortex for $5 \mathrm{~min}$ and left to stand for $24 \mathrm{~h}$. The emulsification index was calculated using Eq. 1 (in triplicate, with average emulsification index reported):

$$
\begin{aligned}
E_{24} & =\frac{\text { Total volume of the emulsion }}{\begin{array}{l}
\text { Total volume of the aqueous solution }+ \text { emulsion } \\
\times 100
\end{array}}
\end{aligned}
$$




\section{Results and discussion}

\section{Process parameters for nanoparticle synthesis}

To develop a suitable method, different parameters were assessed and optimised. The first part of the study focussed on the determination of the optimum $\mathrm{pH}$ and temperature for nanoparticle synthesis. The B. vulgaris solution was used to effectively determine a suitable $\mathrm{pH}$ (high/low acidity and high/low alkalinity). Summarised results for the experimental runs which were used to monitor and confirm the colour change including reaction time are as shown in Table 2-some of which culminated in suitably sized nanoparticles.

During the formation of nanoparticles, a series of colour changes was observed as a result of the betanin which was degraded under different conditions, thus facilitating the reduction of metals to nanosize. As shown in Table 2, there was minimal significant colour change observed in runs $1,2,5$, and 6 under low $\mathrm{pH}$. This indicated that a chemical reaction was non-existent. The $\mathrm{pH}$ normally determines the stability of the betanin, which was previously reported to be stable at a $\mathrm{pH}$ range of 3 to 7 [6]. At this $\mathrm{pH}$ range, betanin loses its ability to bind and reduce metal ions which effectively reduces the synthesis of nanoparticles and thus the yield. For runs 3, 4, and 7 with an alkaline $\mathrm{pH}$, a chemical reaction was observed by a significant colour change in the samples, with no reaction being observed for run 8 at $\mathrm{pH} 10$. In runs 3 and 7, with low alkalinity, the colour changed from purple red to a dark brown colour. The colour change was an indication of betanin degradation, resulting in the formation of a brown colour as previously determined by De Azeredo et al. [6]. At alkaline $\mathrm{pH}$, betanin contains more negatively charged functional groups to efficiently bind and reduce cations.
Additionally, the brown colour is normally observed in the green synthesis of nanoparticles to detect the bioreduction of metals using plant extracts [20, 30]. The slight colour change observed in run 4 can be attributed to the slight degradation of betanin within the samples. Different colour changes for nanoparticle synthesis facilitated by betanin from $B$. vulgaris at different $\mathrm{pH}$ were noted in a study conducted by Parameshwaran et al. [22]. This reaffirmed that $\mathrm{pH}$ affects the stability of the betanin catalysis which promotes subsequent bioreduction of the metal ions. Similarly, elevated temperature promotes betanin degradation and subsequent formation of nanoparticles. Experimental runs 5-8 were performed at ambient temperature under natural light to promote the photocatalytic degradation of the betanin. Minimal colour change was observed in runs 5,6 , and 8 . However, a slow colorimetric reaction was observed for run 7 samples, for which the colour changed from purple red to dark brown after $72 \mathrm{~h}$. This suggested the slow photocatalytic degradation of betanin, as the stability of betanin can also be impaired by natural light [6]. The degradation of betanin in run 7 samples was also enhanced by the alkalinity of the medium compared with samples in runs 5 and 6 . Samples for runs 9 and 10 were both heated to a temperature of $80^{\circ} \mathrm{C}$, which resulted in the gradual colour change from purple red to a dark brown and bright yellow colour, respectively. At elevated temperatures, betanin degradation mechanisms vary. It can either be degraded by isomeration, decarboxylation, or cleavage [24]. During the formation of nanoparticles, elevated temperatures enhance the synthesis process by increasing the nucleation rate [6]; thus, elevated temperatures were observed to increase the reaction rates compared with samples in experiments in which ambient temperatures were used.

To confirm nanoparticle production, TEM was used to characterise the size of the particles (Fig. 1). Furthermore,
Table 2 Summarised comparative analysis of process parameters and observations for nanoparticle synthesis

\begin{tabular}{lrllll}
\hline Sample ID & $\mathrm{pH}$ & $\mathrm{Temp}$ & Supplement & Colour change & Reaction time \\
\hline 1 & 2 & $80{ }^{\circ} \mathrm{C}$ & - & - & - \\
2 & 6 & $80{ }^{\circ} \mathrm{C}$ & - & - & - \\
3 & 8 & $80{ }^{\circ} \mathrm{C}$ & - & Purple red to dark brown & $90 \mathrm{~min}$ \\
4 & 10 & $80{ }^{\circ} \mathrm{C}$ & - & Purple red to dark red & $90 \mathrm{~min}$ \\
5 & 2 & $\mathrm{RT}$ & - & - & - \\
6 & 6 & $\mathrm{RT}$ & - & - & - \\
7 & 8 & $\mathrm{RT}$ & - & Purple red to brown red & $72 \mathrm{~h}$ \\
8 & 10 & $\mathrm{RT}$ & - & - & - \\
9 & 8 & $80{ }^{\circ} \mathrm{C}$ & A. vera and eggshell extract & Purple red to dark brown & $90 \mathrm{~min}$ \\
10 & 8 & $80{ }^{\circ} \mathrm{C}$ & - & Reddish/pink bright yellow & $90 \mathrm{~min}$ \\
\hline
\end{tabular}

$R T$ room temperature

All experiments were performed in triplicate 
Fig. 1 TEM images of the synthesised nanoparticles

\section{A}

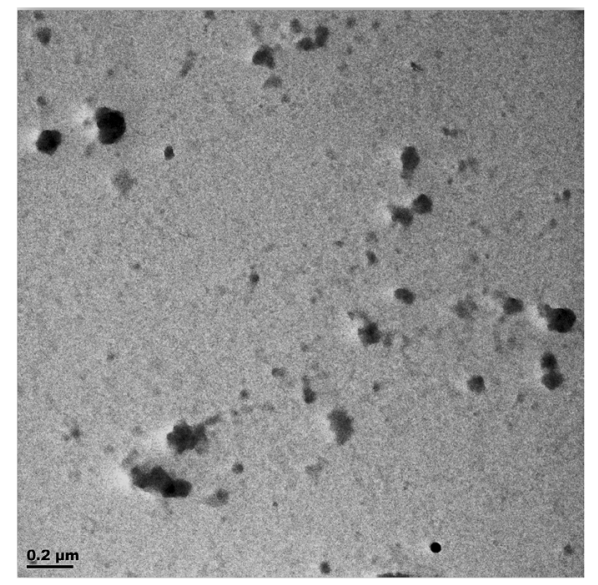

B

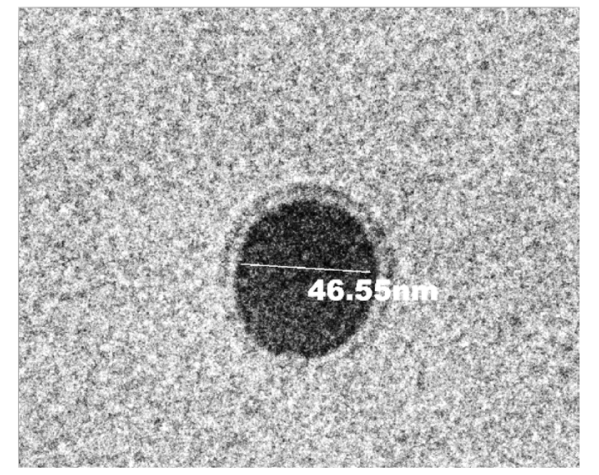

C

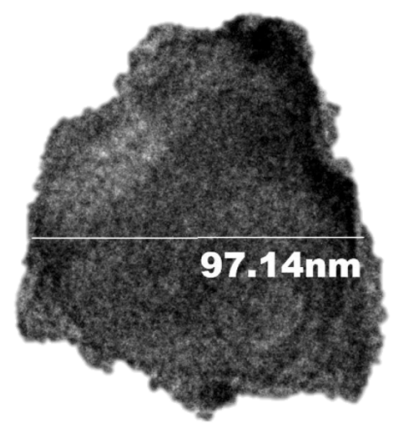

D

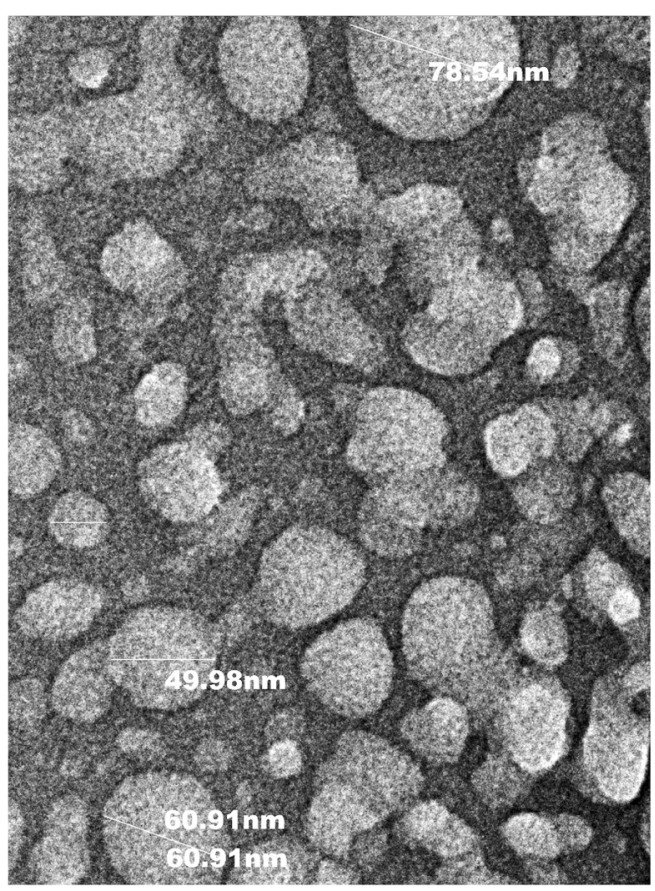

SEM-EDS was also used to confirm the shape and to determine particle composition by performing elemental analysis (Fig. 7). Electron microscope analysis was only carried out on samples that showed a positive chemical reaction. A freshly prepared and untreated $B$. vulgaris juice extract was used in control experiments. For TEM analysis, 
copper grids were coated with a few drops of the samples by using a Pasteur pipette subsequent to drying under a lamp. The grids were also used for SEM-EDS analysis.

The images obtained from the TEM were examined and confirmed the synthesis of nanoparticles. The control experiments showed irregular structures of $0.2 \mu \mathrm{m}$ (Fig. 1a). SEM images for control samples revealed what seemed to be biological debri, i.e. conglomerated gelatinous biomass (pectin-like structures) and/or EPS (Fig. 2ad). EPS, constituting polysaccharides including proteins, is known to aggregate in hyperhaline solutions. Similarly, "low methoxyl pectins form gelatinous structures in the presence of $\mathrm{Ca}^{2+}$ ions at low $\mathrm{pH}(3-4.5)$, whereas high methoxyl pectins rapidly form thermally irreversible gels in the presence of sufficient sucrose at low $\mathrm{pH}^{\prime \prime}[28]-\mathrm{pH}$ and constituents prevalent in untreated $B$. vulgaris juice extracts. These structures are clearly different from those obtained in treated samples, i.e. Fig. 1d. Furthermore, samples for experimental run 3 indicated the formation of well-defined spherical-shaped particles of approximately $46.55 \mathrm{~nm}$. These particles were encapped within a clear capping agent demonstrating betanin's reducing and

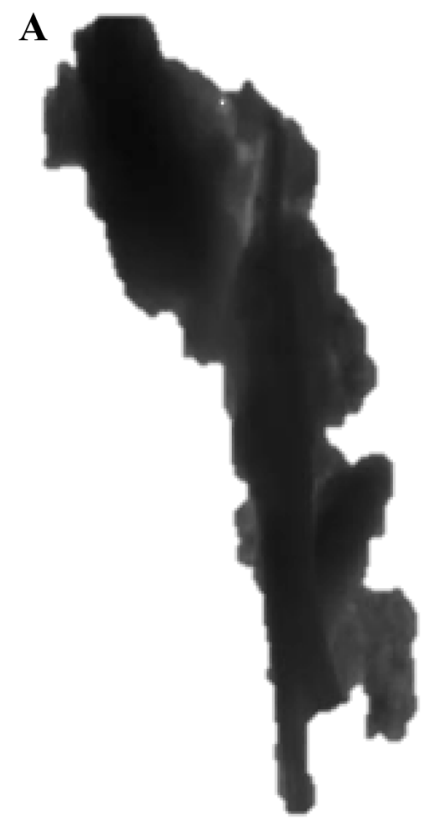

C

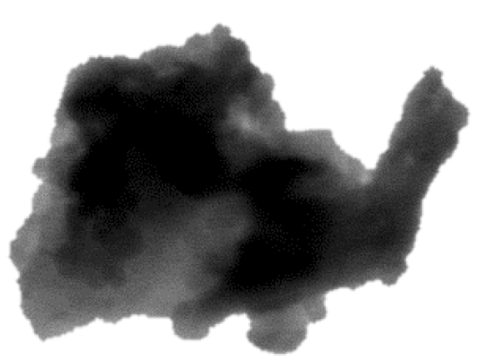

B

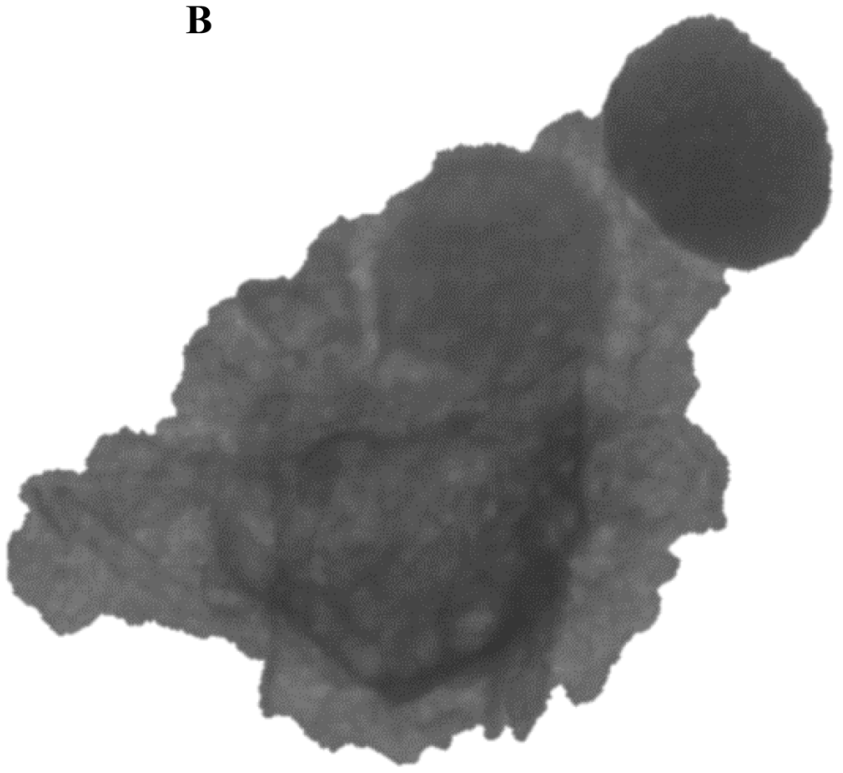

D

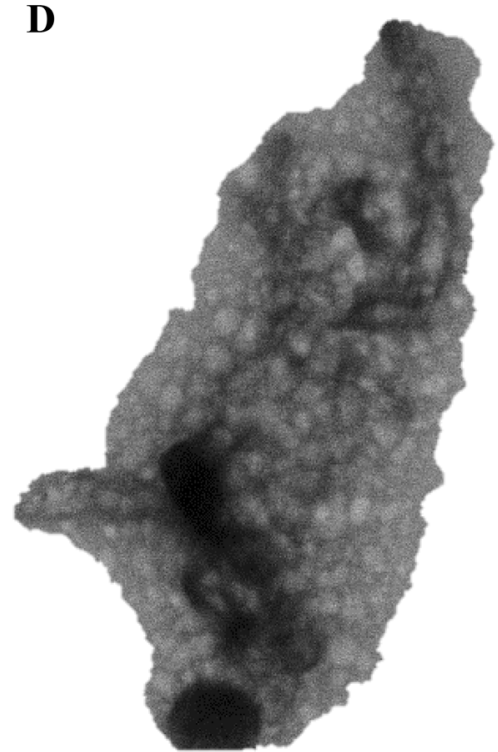

Fig. 2 SEM images of distinguishable biological debri in control experiments (untreated B. vulgaris juice extract) 
Fig. 3 TEM image of the sample supplemented with $A$. vera

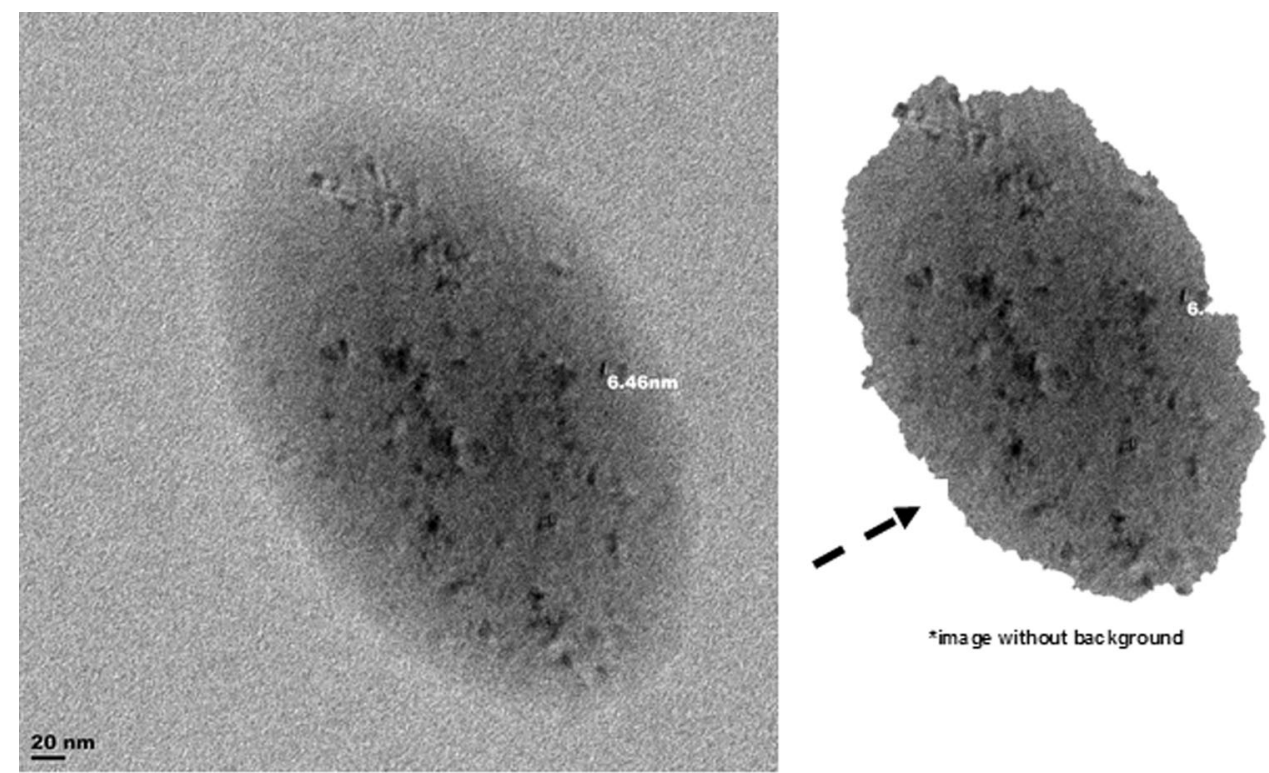

capping capabilities (Fig. 1b), with some larger ( $>50 \mathrm{~nm}$ to $<100 \mathrm{~nm}$ ) irregular nanoparticles (Fig. 1c, d), using a $1 \%$ (v/v) solution from dried B. vulgaris.

TEM and SEM-EDS analyses confirmed sphericalshaped structures of the particle in treated extracts, with elemental analysis, suggesting $\mathrm{Ca}$ as the major constituent. Samples in experimental run 4 indicated an irregularshaped crystal-like structure which falls within the nanosize range (Fig. 1c). No metal constituents were detected from the SEM-EDS spectrum for the irregular-shaped noncrystal-like structures found in samples for run 7 performed under ambient temperature, suggesting EPS conglomeration. $\mathrm{Al}$ and $\mathrm{Si}$ were also detected, presumably as a result of embedded $\mathrm{Al}$ and $\mathrm{Si}$ assumed to be from the soil. On comparing TEM images in samples for run 7 , to those of run 3 (Fig. 1d and b, respectively), the dark shade of the particles was as a result of diffracted light by the crystalline structure of the particles. The light structures observed in TEM images of run 7 samples (Fig. 1d) showed that the particles were large and perhaps irregular in shape. Moreover, spherical crystal particles are formed at high temperatures compared with room temperatures [19], as observed in run 7 , which was processed at room temperature (Table 1). The successful parameters used for samples in run 3 were used for further development of the method. The only limitation of the methods used for the first part of this study was the low yields of the metallic nanoparticles obtained.

\section{Improvement of nanoparticle yields using $A$. vera}

In an attempt to improve yields and optimise the in vitro reaction, biological agents such as $A$. vera can be used as supplements. Equivalent quantities of the B. vulgaris solution and the $A$. vera were added and incubated at $80{ }^{\circ} \mathrm{C}$ and $\mathrm{pH} 8$ for samples in run 9 . For a sustainable greener method, $\mathrm{CaCO}_{3}$ from eggshell extracts was also used to adjust the $\mathrm{pH}$ and as a supplementary source of $\mathrm{Ca}^{2+}$. Eggshells have been reported to be a rich source of mineralised $\mathrm{CaCO}_{3}$, comprising 94\% of the eggshells [21].

The colour change and reaction rate of these samples were similar to those initially observed for run 3 . Therefore, $A$. vera had an insignificant impact on the nanoparticle synthesis, although the colour change was similar to that observed in run 3. However, TEM images (Fig. 3) revealed a decrease in nanoparticle size and an increase in particle yields for samples supplemented with A. vera. This was assumed to be aided by the bioactive phytochemicals in A. vera. The particles synthesised in run 9 were spherical with a size of less than $10 \mathrm{~nm}$. Moreover, A. vera exhibited capping properties, with the nanoparticles synthesised being closely aggregated and encapsulated within the $A$. vera capping agent. The yield and the particle size distribution of the nanoparticles in the samples supplemented with $A$. vera demonstrated an improvement in comparison with those without $A$. vera.

\section{B. vulgaris juice concentration optimisation for nanoparticle synthesis}

Previous studies have shown that the quantity of the plant extracts required during green synthesis of nanoparticles plays a significant role in nanoparticle formation $[9,20,22]$. In this study, B. vulgaris extract solutions were compared with different concentrations of fresh $B$. vulgaris juice, i.e. with experiments (Table 1, experimental runs 
Fig. 4 A series of colour changes for different concentrations (from left to right: Conc.-undiluted juice extract, $10 \%(\mathrm{v} / \mathrm{v}), 1 \%(\mathrm{v} / \mathrm{v})$, and $0.5 \%(\mathrm{v} / \mathrm{v})$ juice extract in water solutions) of $B$. vulgaris juice extract
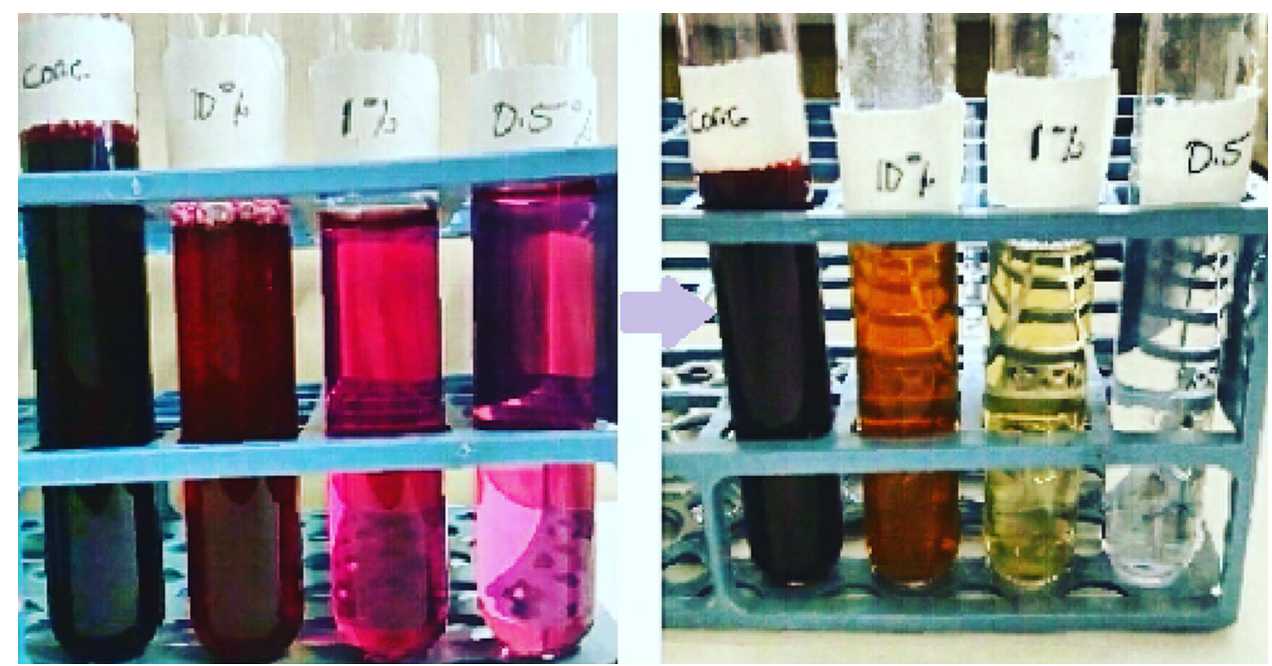

10-13). Experimental run 3 (Table 2) samples, containing B. vulgaris extract solution, were also used for comparative analyses. The fresh juice extract was used within $48 \mathrm{~h}$ of extraction to prevent the solution becoming viscous as a result of moisture loss. B. vulgaris juice extracts containing, $10 \%(\mathrm{v} / \mathrm{v}), 1 \%(\mathrm{v} / \mathrm{v})$, and $0.5 \%(\mathrm{v} / \mathrm{v})($ Table 1$)$ were used. These samples were processed with parameters used successfully in experimental run 3 for nanoparticle synthesis as depicted in Fig. 4, for which a series of colour changes among the samples was observed.

A slight colorimetric reaction of the concentrated sample (labelled conc. in Fig. 4) changed from a dark purple colour to a dark red colour. TEM analysis revealed large crystal-like particles (Fig. 5A) which were closely aggregated and the particle size was above $200 \mathrm{~nm}$, which was above the suitable nanoparticle size range. A series of colour changes was also observed for samples in which $B$. vulgaris juice extracts concentrations were $10 \%(\mathrm{v} / \mathrm{v}), 1 \%$ $(\mathrm{v} / \mathrm{v})$, and $0.5 \%(\mathrm{v} / \mathrm{v})$. Similarly, the samples in which the B. vulgaris juice extracts concentration was $10 \%(\mathrm{v} / \mathrm{v})$ had a colour change that resulted in a brown colour from a red colour, resulting in large rod-like structures (Fig. 5b).

It was important to note that the $B$. vulgaris juice concentration determined the shape including size of the particles being formed, i.e. with higher concentrations resulted in larger particle sizes. Moreover, low concentrations such as $1 \%(\mathrm{v} / \mathrm{v})$ can result in spherical-shaped and well-defined particles. An ideal colour change was observed in samples with a $1 \%(\mathrm{v} / \mathrm{v})$ B. vulgaris juice extract, for which the colour changed from reddish/pink to a bright yellow colour. This colour change indicated the presence of neobetanin. Neobetanin is an isomer of betanin that results in the dehydrogenation of the betanin which generates a bright yellow colour. The hydrolytic cleavage of hydrogen ions is also promoted by an alkaline $\mathrm{pH}$, which in turn determines neobetanin's ability to bind and reduce metal ions during nanoparticle formation. The $1 \%(\mathrm{v} / \mathrm{v})$ B. vulgaris juice extract samples (experimental run 10 in Table 2) showed riveting TEM images (Fig. 5c, used in ImageJ software for particle size distribution).

The results showed higher yields and improved distribution of spherical-shaped nanoparticles confirmed by SEM (Fig. 6) with a size of approximately $5 \mathrm{~nm}$-see insert Fig. 5e, a particle size distribution histogram.

\section{Spectrophotometric characterisation of nanoparticles}

SEM-EDS spectrum (Fig. 7) of the samples for experimental run 10 suggested that calcium ions $\left(\mathrm{Ca}^{2+}\right)$ were the major constituent in the nanoparticles. The absence of oxygen (-O-) from the spectrum was attributed to the fact that the nanoparticles were not of the oxidised form. Cabased nanoparticles synthesised from run 10 included other metals such as $\mathrm{Cu}$, assumed to be from copper grids used and $\mathrm{P}$ in minute quantities. The well-defined nanoparticles obtained in experimental run 10 (Table $2 ; 1 \% \mathrm{v} / \mathrm{v} ; \operatorname{rxn}(\mathrm{t})-$ $90 \mathrm{~min} ; \mathrm{pH} \quad 8 ; 80^{\circ} \mathrm{C}$ ) were used for further characterisation.

UV-Vis spectroscopy was used to establish the absorbtion spectra (Fig. 8) of the metallic nanoparticles synthesised from the $1 \%$ (v/v) B. vulgaris juice extract (run 10). The UV-Vis spectroscopy of the nanoparticle aqueous solution showed absorbance at a wavelength of $418 \mathrm{~nm}$. The bright yellow colour of the aqueous solution was hypothesised to be the surface plasmon of the nascent nanoparticles. Nanoparticles between the size range of 2-100 $\mathrm{nm}$ have a strong and broad surface plasmon peak. This is because the optical absorption spectra of metallic nanoparticles is influenced by surface plasmon resonances (SPR) which move towards longer wavelengths with increases in particle size [20]. The UV-Vis spectrum of the 


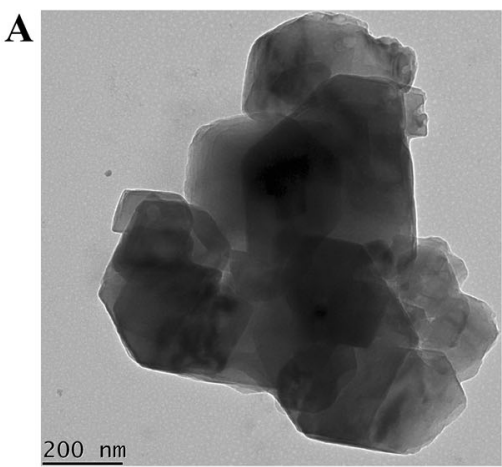

C

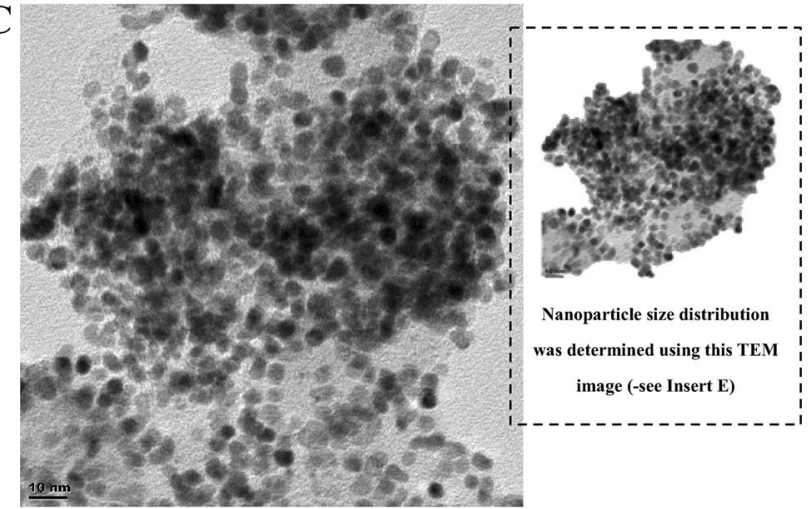

B

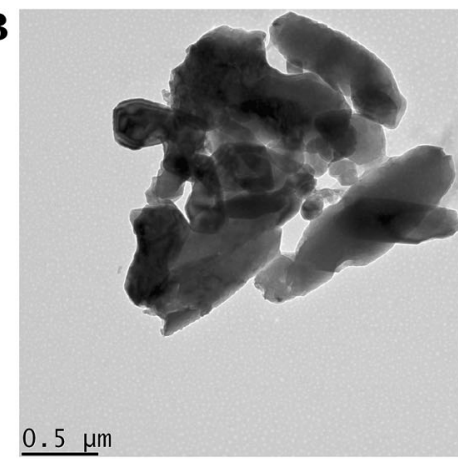

D

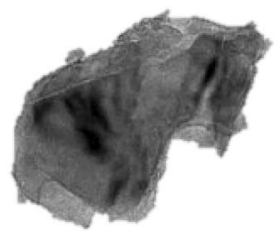

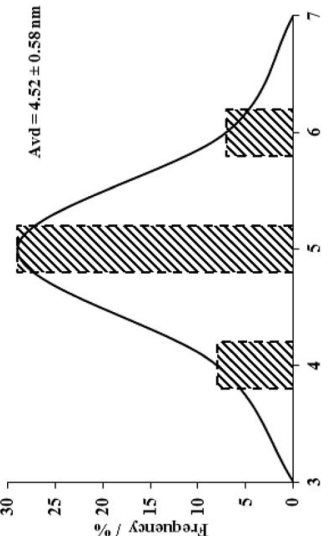

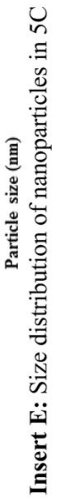

Fig. 5 TEM images for synthesised nanoparticles using different concentrations of $B$. vulgaris juice extract, a Conc.- -undiluted juice extract, b $10 \%(\mathrm{v} / \mathrm{v})$, c $1 \%(\mathrm{v} / \mathrm{v})$, and d $0.5 \%(\mathrm{v} / \mathrm{v})$ juice extract. Insert e) Size distribution using the image in c

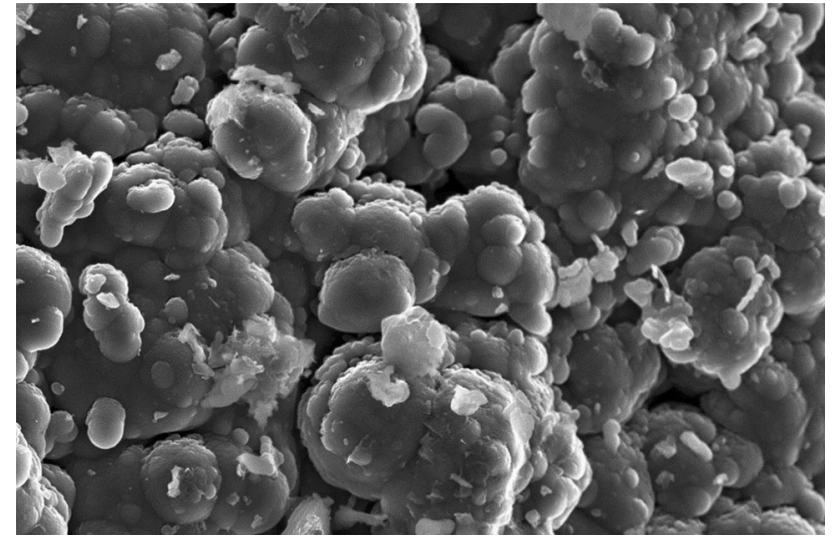

Fig. 6 SEM image of experimental run 10 (Table 2, 1\% v/v juice extract)

aqueous solution presented a single SPR band which disclosed the spherical-shaped characteristics of the nanoparticles. This phenomenon is supported by Mie's theory which briefly states that "a single SPR results in spherical-shaped nanoparticles" [18]. These findings were confirmed by SEM images of run 10, which showed the synthesis of spherically shaped nanoparticles (as shown in Fig. 6).

The crystallisation aspects of the synthesised nanoparticles were analysed using powder $\mathrm{X}$-ray diffraction
(PXRD). PXRD is a non-destructive technique that allows analysis of unknown materials in terms of crystallinity and phase identification [29]. The PXRD pattern of the synthesised nanoparticles presented sharp narrow peaks which revealed the formation of crystal nanoparticles-Fig. 9.

The diffracted peaks originating at the 2 theta degrees illustrated the characteristics of calcium line indexed at (001) and (100) with diffraction angles of 18.0 and 28.6, respectively. Therefore, it was presumed that crystal Cabased nanoparticles were successfully synthesised. The peaks exhibited in the diffractogram were in accordance with JCDDS file 87-0315 for $\mathrm{Ca}(\mathrm{OH})_{2}$ nanoparticles reported by Darroudi et al. [5]. The presence of unidentified peaks in the pattern may be a result of metallic impurities in the sample also shown in Fig. 7 [22, 30].

To determine the reduction mechanism of the metals and betanin within the B. vulgaris extract juice, FTIR analysis was also conducted. The FTIR spectrum of a sample from run 10 (Fig. 10) showed transmissions at $3270 \mathrm{~cm}^{-1}$, corresponding to a hydroxyl $(\mathrm{OH})$ vibration band. This suggested that a proton dissociated from the $\mathrm{OH}$ group, accompanied by a reduction of metal ions. From the FTIR spectra, carbonyl groups exhibited a stretching frequency at $1634.03 \mathrm{~cm}^{-1}$. The presence of these molecular groups provides stability and capping of nascent nanoparticles. This also suggested that the nanoparticles were 
Fig. 7 SEM-EDS spectrum of a sample in experimental run 10

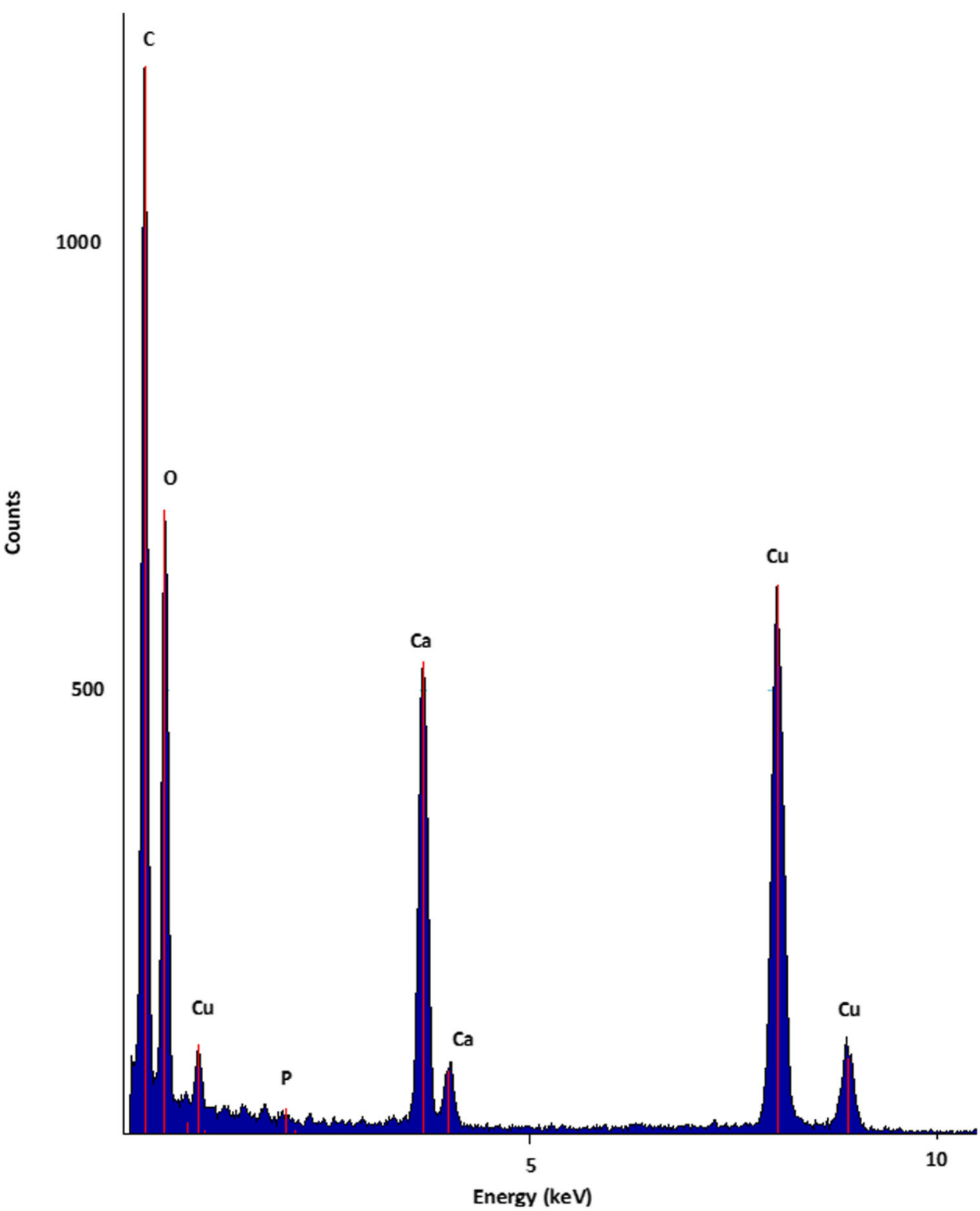

capped by a polymer as shown in Fig. 1B for experimental run 3 . The general decrease in the bands observed between 571.87 and $406.09 \mathrm{~cm}^{-1}$ indicated metallic nanoparticles synthesis facilitated by betanin. At this point, the functional groups of betanin interacted with the metals found in $B$. vulgaris juice for the formation of nanoparticles. A similar trend was observed in the FTIR spectrum for betanin, i.e. for the analysis of the surface structure of Ag nanoparticles [22]. This suggested that there was a reaction between free metal ions and betanin found in $B$. vulgaris for the formation of nanoparticles, a hypothesis used to elucidate the mechanism for the synthesis of the Ca-based nanoparticles.

Overall, the synthesised nanoparticles can be used in enhancing the bioavailability of hydrophobic recalcitrant persistent organic pollutants in bioremediation studies-
Sect. 3.5 demonstrates the application of the produced nanoparticles reported in this study.

\section{Nanoparticles from Beta vulgaris: an environmental engineering application}

The nanoparticles synthesised were used in a system utilised to produce biosurfactants in fed-batch fermentations. Subsequently, kerosene was emulsified using the biosurfactants produced by Bacillus licheniformis STK 01 in $B$. vulgaris media supplemented with the Ca-based nanoparticles. Table 3 shows the emulsification index of kerosene by Bacillus licheniformis STK 01-Ca-based nanoparticle extracts; results which were compared with those obtained in a previous study by Amodu et al. [3]. The emulsification 
Fig. 8 UV-Vis spectrum of a sample for experimental run 10

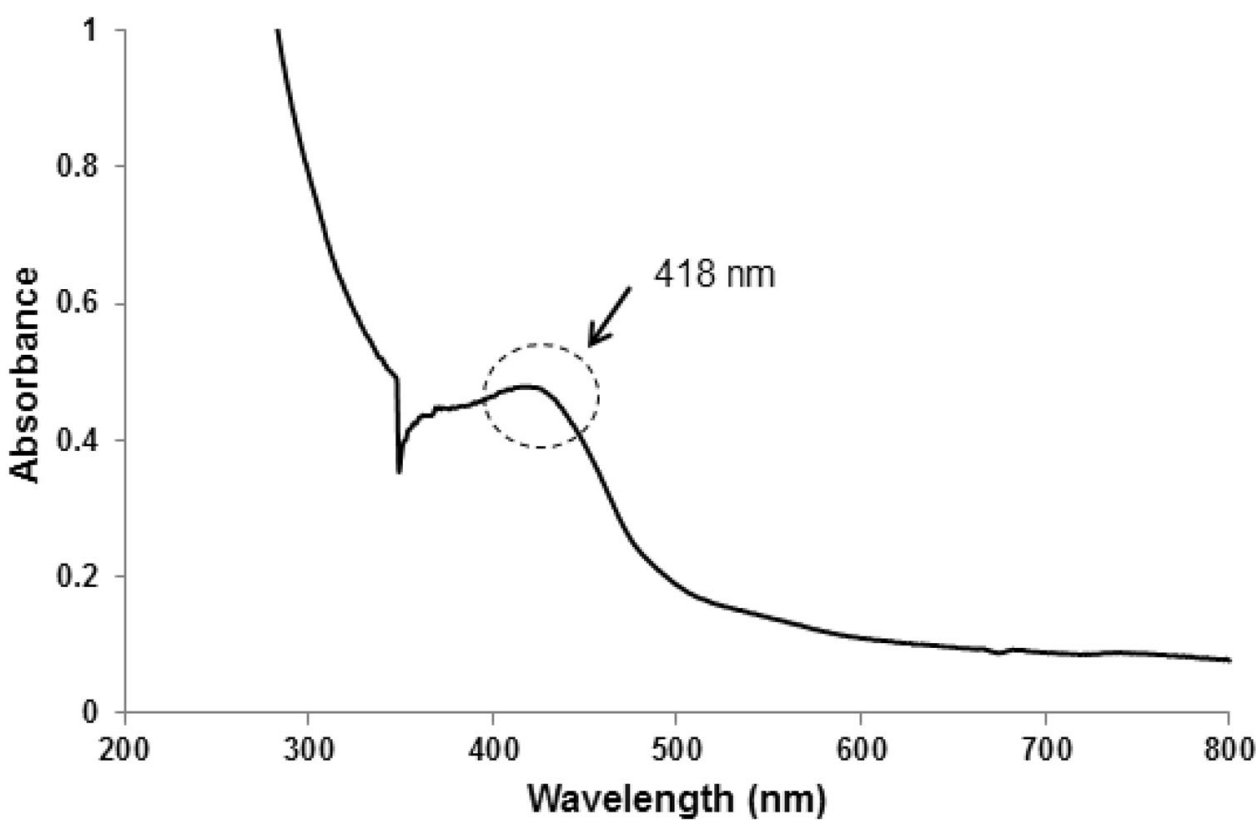

Fig. 9 PXRD pattern of $\mathrm{Ca}-$ based nanoparticles obtained from a sample in experimental run 10

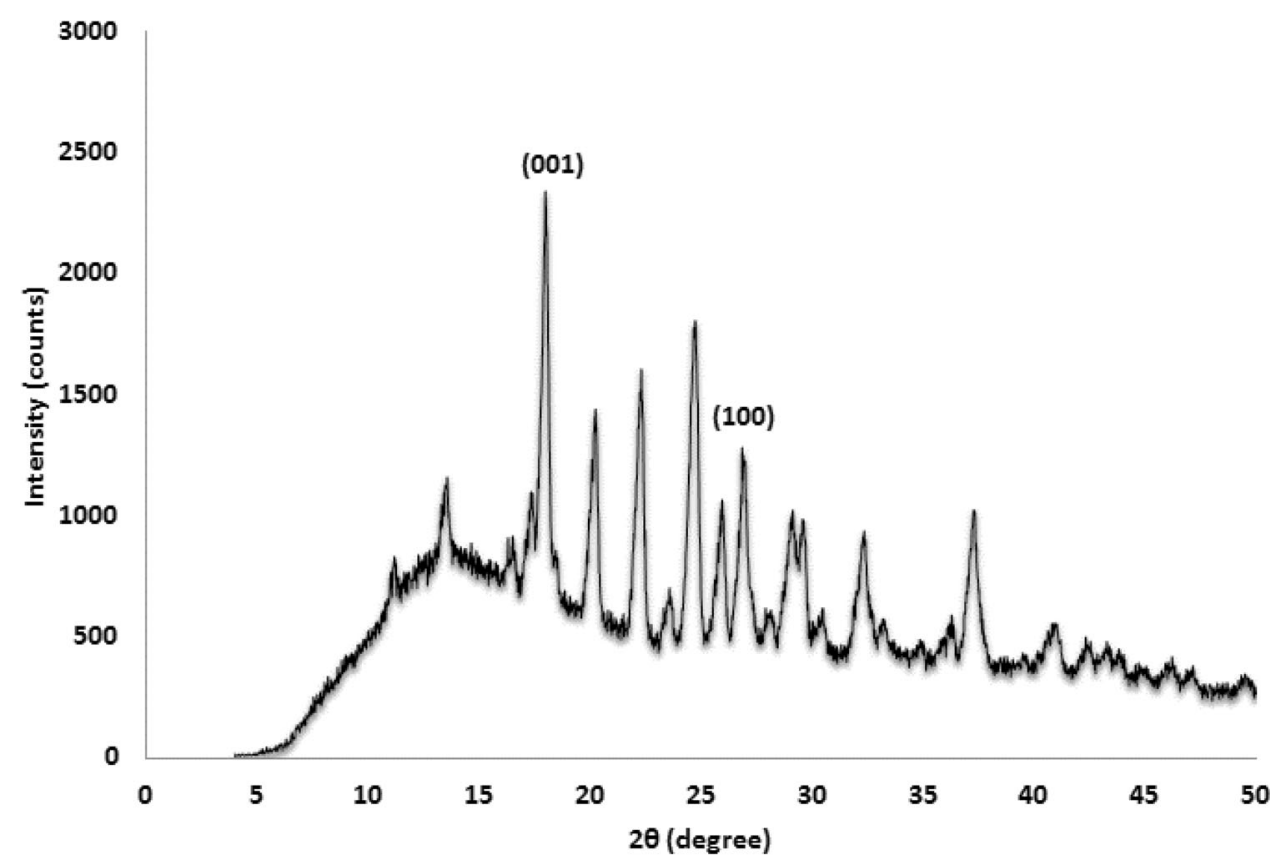

index of kerosene in this study was determined to have increased to $50 \%$, and the emulsion was stable for over $24 \mathrm{~h}$.

The biosurfactants produced by Bacillus licheniformis STK 01 exclusively on B. vulgaris were previously identified as effective emulsifiers for a variety of hydrocarbons except for kerosene [3]. This study showed that the supplementation of the culture with Ca-based nanoparticles synthesised, culminated in biosurfactants with improved emulsification index of kerosene as compared to the results obtained by Amodu et al. [3], using the same organism and fermentor. The biosurfactant-Ca-based nanoparticle extracts formed stable emulsions, a result attributed to the nanoparticles. The addition of Ca-based biocompatible nanoparticles increased the stability of the kerosene emulsion by forming a semi-solid layer between the oilwater phases. Overall, the nanoparticles and the amphiphilic nature of the biosurfactants cooperatively aided in the stability of the kerosene emulsions. A similar phenomenon was previously described by Józefczak and Wlazło [11], whereby positively charged surfactant head groups adsorbed on to the surface of hydrophilic magnetic 
Fig. 10 FTIR spectrum of a sample from experimental run 10

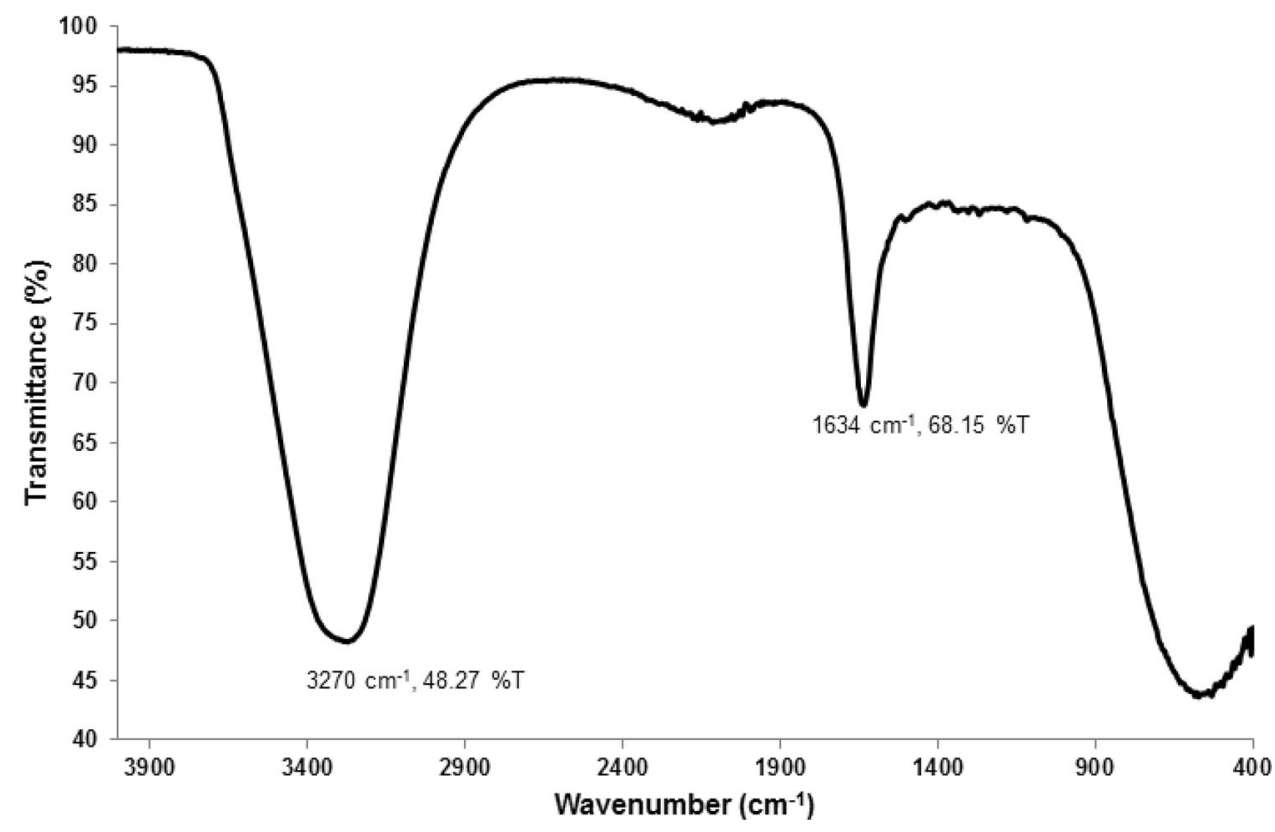

Table 3 Emulsification of kerosene by Bacillus licheniformis STK 01/Ca-based nanoparticle extracts

\begin{tabular}{ll}
\hline References & $\mathrm{E}_{24}$ \\
\hline Amodu et al. $[2,3]$ & $20 \%$ \\
This study & $50 \%$ \\
\hline
\end{tabular}

nanoparticles, exposing hydrophobic tails, which aided the stabilisation of emulsions studied.

\section{Conclusion}

A single-pot green chemistry method for the synthesis of Ca-based nanoparticles using B. vulgaris extracts was developed. It can be concluded that elevated temperatures and alkaline $\mathrm{pH}$ conditions influence the bioreduction of metal ions accumulated in B. vulgaris, which were converted into nanoparticles. Electron microscopes and spectrophotometric analysis revealed the successful synthesis of spherical-shaped Ca-based crystal nanoparticles of approximately $5 \mathrm{~nm}$ following bioreduction by betanin. Furthermore, the supplementation of the synthesised nanoparticles in a fed-batch biosurfactant production system culminated in improved emulsification activity of the biosurfactant produced as demonstrated by the improved emulsification of kerosene. Overall, nanoparticles from Beta vulgaris can be applied in environmental engineering applications such as the bioremediation of hydrophobic contaminants in polluted environments.

Acknowledgements The authors would like to acknowledge the funding from the Cape Peninsula University of Technology (CPUT)
University Research Fund (URF RK 16) and National Research Foundation (NRF).

\section{References}

1. Ahmed S, Ahmad M, Swami B, Ikram S (2016) A review on plants extract mediated synthesis of silver nanoparticles for antimicrobial applications: a green expertise. IJAR 7(1):17-28

2. Amodu OS, Ntwampe SK, Ojumu TV (2014) Emulsification of hydrocarbons by biosurfactant: exclusive use of agrowaste. BioResources 9(2):3508-3525

3. Amodu OS, Ntwampe SKO, Ojumu TV (2014) Optimization of biosurfactant production by Bacillus licheniformis STK 01 grown exclusively on Beta vulgaris waste using response surface methodology. BioResources 9(3):5045-5065

4. Basu S, Maji P, Ganguly J (2015) Rapid green synthesis of silver nanoparticles by aqueous extract of seeds of Nyctanthes arbortristis. J Appl Nanosci 6(1):1-5. doi:10.1007/s13204-015-0407-9

5. Darroudi M, Bagherpour M, Hosseini HA, Ebrahimi M (2016) Biopolymer-assisted green synthesis and characterization of calcium hydroxide nanoparticles. Ceram Int 3(42):3816-3819. doi:10.1016/j.ceramint.2015.11.045

6. De Azeredo HMC, Pereira AC, De Souza ACR, Gouveia ST, Mendes KCB (2009) Study on efficiency of betacyanin extraction from red beetroots. Int J Food Sci Technol 44(12):2464-2469. doi:10.1111/j.1365-2621.2009.02037.x

7. Dhand V, Soumya L, Bharadwaj S, Chakra S, Bhatt D, Sreedhar B (2016) Green synthesis of silver nanoparticles using Coffea arabica seed extract and its antibacterial activity. Mat Sci Eng C Biol S 58:36-43. doi:10.1016/j.msec.2015.08.018

8. Edison T, Lee Y, Sethuraman M (2016) Green synthesis of silver nanoparticles using Terminalia cuneata and its catalytic action in reduction of direct yellow-12 dye. Spectrochim Acta A 161:122-129. doi:10.1016/j.saa.2016.02.044

9. Gan PP, Ng SH, Huang Y, Li SFY (2012) Green synthesis of gold nanoparticles using palm oil mill effluent (POME): a low-cost and eco-friendly viable approach. Biores Technol 113:132-135. doi:10.1016/j.biortech.2012.01.015 
10. Ghaedi M, Yousefinejad M, Safarpoor M, Khafri H, Purkait M (2015) Rosmarinus officinalis leaf extract mediated green synthesis of silver nanoparticles and investigation of its antimicrobial properties. Ind Eng Chem Res 31:167-172. doi:10.1016/j.jiec. 2015.06.020

11. Józefczak R, Wlazło R (2015) Ultrasonic studies of emulsion stability in the presence of magnetic nanoparticles. Adv Condens Matter Phys. doi:10.1155/2015/398219

12. Kalimuthu K, Suresh Babu R, Venkataraman D, Bilal M, Gurunathan S (2008) Biosynthesis of silver nanocrystals by Bacillus licheniformis. Colloids Surf B Biointerfaces 65(1):150-153. doi:10.1016/j.colsurfb.2008.02.018

13. Kiran GS, Nishanth LA, Priyadharshini S, Anitha K, Selvin J (2014) Effect of Fe nanoparticle on growth and glycolipid biosurfactant production under solid state culture by marine Nocardiopsis sp. MSA13A. BMC Biotechnol 14(1):1-10. doi:10. 1186/1472-6750-14-48

14. Kiran GS, Selvin J, Manilal A, Sujith S (2011) Biosurfactants as green stabilizers for the biological synthesis of nanoparticles. Crit Rev Biotechnol 31(4):354-364. doi:10.3109/07388551.2010. 539971

15. Kowalczyk B, Lagzi I, Grzybowski BA (2011) Nanoseparations: strategies for size and/or shape-selective purification of nanoparticles. Curr Opin Colloid Interface Sci 16(2):135-148. doi:10.1016/j.cocis.2011.01.004

16. Kumar S, Sharma JK (2016) Stable phase CdS nanoparticles for optoelectronics: a study on surface morphology, structural and optical characterization. Mater Sci Poland 34(2):368-373. doi:10. 1515/msp-2016-0033

17. Le VH, Thuc CNH, Thuc HH (2013) Synthesis of silica nanoparticles from Vietnamese rice husk by sol-gel method. Nanoscale Res Lett 8(1):58. doi:10.1186/1556-276X-8-58

18. Link S, El-Sayed MA (2000) Shape and size dependence of radiative, non-radiative and photothermal properties of gold nanocrystals. Annu Rev Phys Chem 19(3):409-453. doi:10.1080/ 01442350050034180

19. Makarov VV, Makarova SS, Love AJ, Sinitsyna OV, Dudnik AO, Yaminsky IV, Taliansky ME, Kalinina NO (2014) Biosynthesis of stable iron oxide nanoparticles in aqueous extracts of Hordeum vulgare and Rumex acetosa plants. Langmuir 30:5982-5988. doi:10.1021/la5011924
20. Mubayi A, Chatterji S, Rai PM, Watal G (2012) Evidence based green synthesis of nanoparticles. Adv Mater Lett 3(6):519-525. doi:10.5185/amlett.2012.icnano.353

21. Murakami FS, Rodrigues PO, De Campos CMT, Silva MAS (2007) Physicochemical study of $\mathrm{CaCO}_{3}$ from egg shells. Ciênc Technol Aliment 27(3):658-662. doi:10.1590/S010120612007000300035

22. Parameshwaran R, Kalaiselvam S, Jayavel R (2013) Green synthesis of silver nanoparticles using $B$. vulgaris: role of process conditions on size distribution and surface structure. Mater Chem Phys 140(1):135-147. doi:10.1016/j.matchemphys.2013.03.012

23. Płaza GA, Chojniak J, Banat IM (2014) Biosurfactant mediated biosynthesis of selected metallic nanoparticles. Int $\mathrm{J}$ Mol Sci 15(8):13720-13737. doi:10.3390/ijms 150813720

24. Reshmi SK, Aravindhan KM, Suganyadavi P (2012) The effect of light, temperature, $\mathrm{pH}$ on stability of betacyanin pigments in Basella alba fruit. Asian J Pharm Clin Res 4(3):107-110

25. Rodríguez Arredondo M, Kuntke P, Jeremiasse A, Sleutels T, Buisman C, ter Heijne A (2015) Bioelectrochemical systems for nitrogen removal and recovery from wastewater. Environ Sci Water Res Technol 1(1):22-33. doi:10.1039/C4EW00066H

26. Sadeghi B, Gholamhoseinpoor F (2015) A study on the stability and green synthesis of silver nanoparticles using Ziziphora tenuior $(\mathrm{Zt})$ extract at room temperature. Spectrochim Acta Mol Biomol Spectrosc 134:310-315. doi:10.1016/j.saa.2014.06.046

27. Singh B, Hathan BS (2014) Chemical composition, functional properties and processing of beetroot-a review. IJSER 5(1):679-684

28. Srivastava P, Malviya R (2011) Sources of pectin, extraction and its applications in pharmaceutical industry-an overview. Indian J Nat Prod Resour 2(1):10-18

29. Taglieri G, Mondelli C, Daniele V, Pusceddu E, Trapanati A (2013) Synthesis and X-ray diffraction analysis of calcium hydroxide nanoparticles in aqueous suspension. AMPC 3(1A):108-112. doi:10.4236/ampc.2013.31A013

30. Usman MS, Ibrahim NA, Shameli K, Zainuddin N, Yunus WMZW (2012) Copper nanoparticles mediated by chitosan: synthesis and characterization via chemical methods. Molecules 17(12):14928-14936. doi:10.3390/molecules171214928 